brother grew four inches in less than a year under similar treatment, as recorded by Dr. 'I'. ('. Railton. ${ }^{2}$ As a point in the practical treatment of these cases I have found that during thyroid treatment this rapid growth of the skeleton leads to a softened condition of the bones, resulting in a yielding and bending of those which have to bear weight; and as cretins under treatment become much more active and inclined to run about this tendency to bending has to be guarded against. The girl, aged seventeen and three-quarter years, of whom photographs are reproduced, shows this increased bending of the legs very well. She has now been continuously under thyroid treatment for two and a quartex years, taking one five-grain tabloid (B. and W.) daily with her dinner, and

$$
\text { Frg. } 2 .
$$

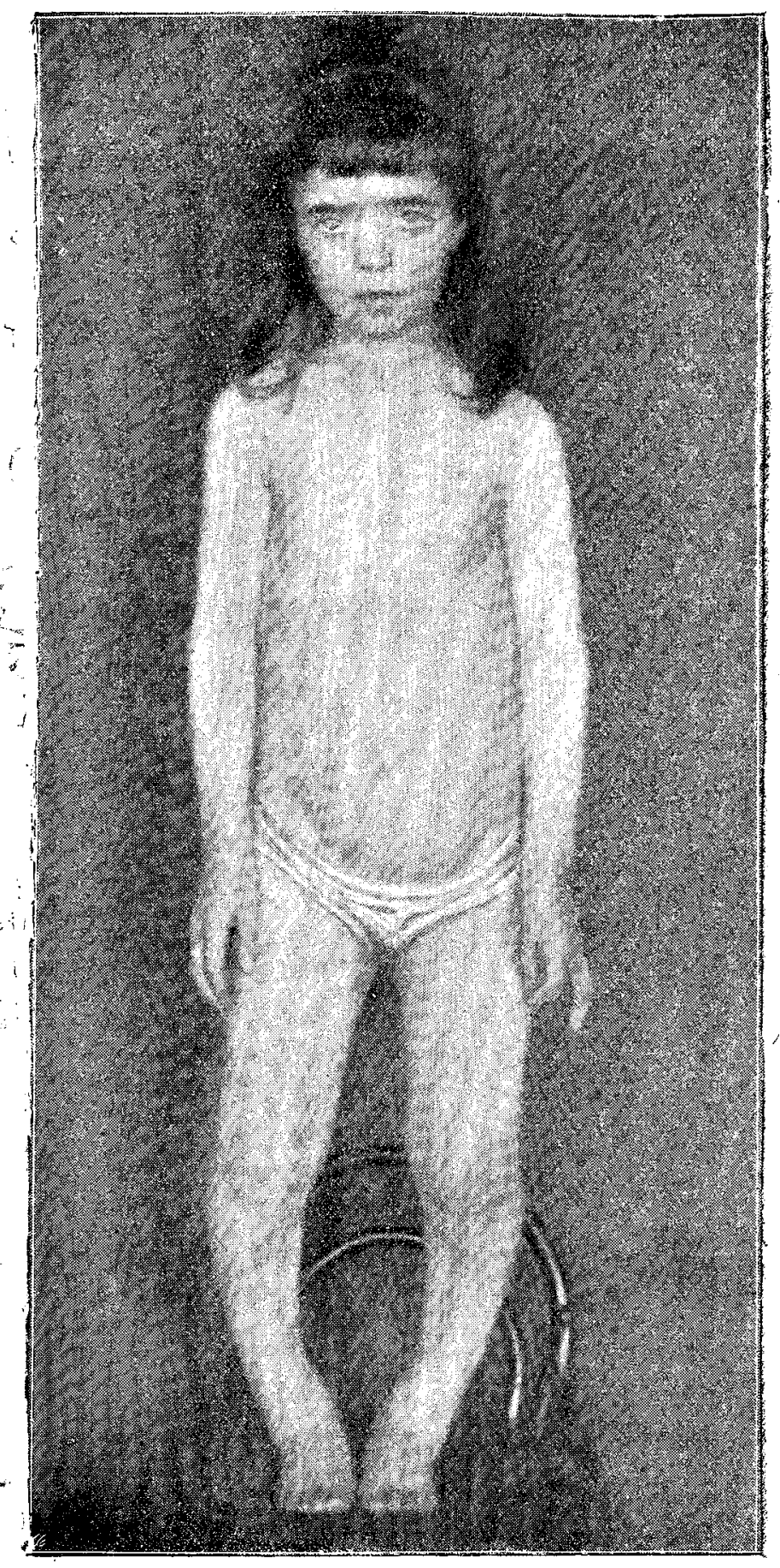

The patient at the age of seventeen years and nine months (after two and a quarter years' thproid treatment). Height, $4 \mathrm{ft}$. $1 \frac{1}{2}$ in.; weight, $4 \mathrm{st}$. $10 \mathrm{t}$ lb. Showing increased bowing of legs and enlargement of knees and ankles.

during that period she has grown seven and a balf inches (from $3 \mathrm{ft}$. 6 in. to $4 \mathrm{ft} .1 \frac{1}{2}$ in.). During the period of two years previous to treatment she had only grown an inch ${ }^{3}$ (from $3 \mathrm{ft.} 5 \mathrm{in}$. to $3 \mathrm{ft} .6 \mathrm{in.}$. (Fig. 1.) Yor the last few months she bas been kept as far as possible at rest, so as to

2 Sporadic Cretinism Treated by Administration of the Thyroid Gland, Brit. Med. Jour., June 2nd, 1894.

3 Cases of Sporadic Cretinism Treated by Thyroid Extract, by Dr. T. Telford-Smith, Journal of Mental Science, April, 1895. prevent, to some degree, this bending of the legs. The second photograph shows that the bending takes place most. markedly in the tibia and fibula, the increased size of the ends of these bones at the ankle and knee being very noticeable. Several of the photographs of cretins before and after thyroid treatment exhibited by Dr. W. R. Parker, of Kendal, and Dr. John Thomson, of Edinburgh, at the meeting of the British Medical Association at Carlisle, showed this increased bending of the legs very clearly, and the condition was remarked upon and discussed, Mr. Victor Horsley showing in this connexion slides to illustrate rickets produced in rabbits by Hoffmeister, and in sheep and goats by von Eisenburg, by removal of the thyroid gland.

While in rickets, however produced, there is perverted and delayed ossification resulting in softening and bending of the bones, under thyroid treatment in cretinism there is rapid resumption of growth in the skeleton, leading to softening, which is most marked in the long bones and at the epiphyses. Cretins under thyroid treatment should, therefore, be watched for any commencing bending of the bones of the legs, and if such appears the child should for a time be hindered from walking or the legs supported by light splints. As an additional means of assisting the rapia bone and other growth the diet should be generous and the child should get plenty of sunlight and open air. The administration of cod-liver oil and Parrish's food would probably prove beneficial at the same time.

Lancaster.

\section{A CASE OF ADVANCED CRETINISM TREATED BY THYROID EXTRACT.}

BY H. E. DRAKE-BROCKMAN, F.R.C.S. EDIN., SURGEON-CAPTAIN, INDIAN MEDICAL SERVICE.

AT the present time, when the treatment of certair: diseases by the administration of thyroid extract is more or less $s u b$ judice, the following case of a marked cretin which came under my care and was subjected to this treatment may prove of interest to the profession.

A boy, caste Dhobi, was one day brought to me by his father for examination suspected of being an idiot. A cursory inspection of the youth was sufficient to reveal his true condition-viz., that of a marked cretin. It appeared on inquiry from his parents that the disease first showed itself in the lad about six years before in the shape of deafness, followed by dulness of intellect, slowness in perception of things said to him, dilatoriness in movement, coupled with a want of coördination, which ultimately dereloped into the usual waddling gait. At the first inspection he presented more or less all the typical symptoms of a cretin, in that he had the usual heary, dull expression of countenance, the mouth half open, with saliva dribbling over the chin, the tongue protruding between the teeth, the eyelids puffy, with a very platyrrhine nose and brachycephalic head; his figure was squatty, but not much deformed. There was slight tendency to exophthalmos, the thyroid was distinctly enlarged, and the superficial skin covered with distended veins, more so to the right side, where the tumour was markedly tense and somewhat elastic to the touch, rather suggestive of the presence of cystic growth. Over the point of most prominence on auscultation there was a marked bruit, slightly musical in character. Measurement of the neck round the tumour accurately taken

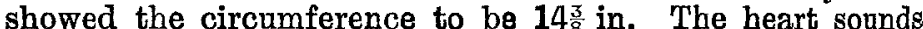
were normal, and so were those of the lungs, with the exception of slight stridor noticeable over the enlarged thyroid, owing probably to pressure of the growth on the trachea. The urine was also analysed and was found to be of specific gravity 1025, reaction acid, and contained neither albumin nor sugar. Towards the end of November last the thyroid treatment was begun by administration of three grains of the dry extract by the mouth daily. After the lapse of one month the boy was again thoroughly examined and the following note was made by me at the time: "The boy's whole appearance has improved most markedly, his sense of hearing and perception of things said to and around him is much acuter, the eyelids are much less puffy, and his gait has also lost some of its waddling character; be bas. 
been able to walk four miles daily for the last week. The thyroid enlargement also was carefully measured by me to-day in the exact spot as before and was found to be 123in.; the tumour itself has become much softer, and the bruit mentioned above has very nearly disappeared." It will be seen from the note taken that the thyroid enlargement had diminished fally 2 in. since the commencement of the treatment-that is, in the space of one month the gland had markedly atrophied-and the general condition of the lad, both physically and mentally, has shown marked improvement. Seeing that the treatment had acted so beneficially I decided to increase the dose to five grains daily, which was accordingly done. A whole month was allowed to elapse from this date, the lad being under daily observation as before and the medicine daily administered. At the end of the month-that is, two from the date of the commencement of the treatment-a thorough examination of the boy was again made, and the following note was registered: "The bodily condition of the patient has again showed steady improvement, his hearing and intellect are much improved, the boy can run now, and has hardly anything left of the waddling gait. The measurement of the tumour was again taken to-day and found to be only 12in. and the neck of the patient has assumed a more or less normal aspect; there is no bruit audible at all in the spot previously noticed. The marked and steady improvement registered in the last note still continues." The treatment, as above indicated, was continued without stopping daily for another month, at the end of which a still further improvement was noted in every respect, the boy could at once interpret what was said to him and reply to it in an audible voice, and with clearness too. At this examination I noticed a marked absence of patellar reflex, this being a prominent symptom in tabes dorsalis, in which it had been stated by the late Professor Brown-Séquard that orchitic fluid had worked wonders. I decided to try the effect of it in this case, and so administered to him five grains of didymin daily as well as the thyroid extract. After the lapse of a fortnight there were signs of the reflex returning, he certainly became much stronger on his legs, and could run if desired; he latterly used to walk about eight miles daily to come to see me, when, to my regret, having to leave the district on transfer to another station, I have in consequence lost sight of the lad, and thas a most interesting inquiry has been unavoidably and abruptly terminated. I took the opportunity of obtaining a sample of the water usually consumed by the patient and his family and sent it for analysis to the chemical examiner, who found that the water contained 44.8 grains per gallon of total solids, the greater portion of which was lime salts. There is not much information to be gained by the family history of the patient, which is briefly as follows. The father is alive and free from any disease, as I have had ample opportunities of verifying for myself. The mother died years ago, and used to suffer from what is described as epilepsy. There is no history of syphilis; there are two children, both males, the elder a youth of about nineteen years of age, and perfectly healthy, whom I have also seen for myself ; the younger son (this patient) a lad of about sixteen years old, who is a marked cretin. It is interesting to note that the boy's home is at the foot of the hills in a kind of country in which cretins are usually expected to be found, and $I$ hear, on inquiry, though I have not been able to verify it, that there are a few in the neighbourhood.

Since the above case I have come across one somewhat similar, treated and reported by Dr. Rushton Parker, of Kendal, quite independently of and unknown to me, which I have read with great interest, though the two cases differed somewhat materially in many little ways, as will be seen on reference to them ; both cases, however, improved so wonderfully under this treatment that it gives one great hopes that something more than temporary relief may be ensured by it. The case above narrated has a great many points of interest attached to it, in that it was an advanced one, not only in years, but in severity of its symptoms, the rapid diminution, which I presume was simple atrophy of the thyroid tumour after the administration of the drug, also the rapid and marked improvement which took place in both the patient's mental and physical condition, notwithstanding the comparatively short time that he was subjected to the thyroid treatment. Though I am fully aware that the case is more or less incomplete, still the benefits derived by the patient at my hands under this treatment in so short a period afford me sufficient excuse for bringing this case to the notice of the profession, in the hope that others who have greater facilities than myself for treating the disease may be induced to give it a fair trial and record their experiences.

Bengal.

\section{NOTES ON A CASE OF CRETINISM SUCCESSFULLY TREATED WITH THYROIDIN.}

\section{By C. MORTON ANDERSON, M.R.C.S. ENG.}

IN the early part of $1893 \mathrm{I}$ had read with much interest the accounts published in the English medical journals of several cases of cretinism which had been successfully treated by the administration of the thyroid gland of the sheep or of some of the many preparations which were being made from that gland. In the latter part of that year I had an opportunity through the kindness of Dr. Ord and others of seeing many of those patients whom I had previously been reading about. as well as several others, and of judging of the results for myself. I was very much impressed with what I saw, the change for the better in many of the patients being marvellous; but I do not remember seeing one, especially in so old a child, in which the result of treatment was more striking than in the case related in the following notes. The accompanying illustrations from photographs, though very imperfect (being my first attempt at photography), will perhaps show better than words the physical condition of the patient before and after treatment. The patient, a girl aged eleven years, first showed symptoms of cretinism when about three years of age. She had been under professional treatment in various ways previously, but with no good result. Early in 1893 I had put her on a strict dietary for nearly three months but with very little benefit, and on Jan. 1st, 1894, she weighed $4 \mathrm{st} .7 \mathrm{lb}$. in her ordinary clothes, and measured $3 \mathrm{ft} .4 \frac{1}{2}$ in. in height, a gain of three-quarters of an inch having been made during the previous year. This gain, though small, had been the greatest she had made for some years. On Jan. 16th, 1894, her features were thick and blunted and she was excessively corpulent. There were large supra-clavicular folds of fat and there was a large hump of the same substance over the lower cervical and upper dorsal vertebræ. She felt like a dead weight when lifted, and the skin, which was cold to the touch, felt harsh and dry. Her hair was long and thick; her appetite was poor, but the bowels were fairly regular and she slept well. The child's intelligence was decidedly dulled and slow, and there was great want of animation; she drawled her words and spoke slowly and in a deep, peculiar voice. She had been at school for a year and a half but could only spell a few monosyllables or add up three or four figures. The circumference of the chest was $24 \frac{1}{2}$ in. and of the abdomen $27 \frac{1}{2}$ in. (See Fig. 1, which was taken at this time.) The pulse was 60 . I ordered $2 \frac{1}{2}$ gr. of thyroidin to be given every second day, which $I$ increased to $5 \mathrm{gr}$. on Jan. 23rd. On Feb. 2nd the temperature was $98.6^{\circ} \mathrm{F}$, and the pulse 78. She was much brighter and more animated. The clavicular folds and the cervical hump were decidedly softer and rather smaller. The digestive functions were not in the least disturbed and the appetite had improved. I ordered one 5-gr. tablet daily. On Feb. 23rd the patient weighed 4st. 11b. The temperature was normal, the pulse 100, and the skin moist and supple. She was very much sharper and more animated and cheerful, becoming quite hilarious and playful. The abdomen was not nearly so large and the clavicular folds were fast disappearing, but the cervical hump looked quite as prominent. I ordered a 5 -gr. tablet to be given each morning and half a tablet each afternoon. On March 14th the patient's height was $3 \mathrm{ft} .5 \mathrm{in}$. and her weight 3 st. $12 \frac{1}{2} \mathrm{lb}$, , being a gain of half an inch in height and a loss of $8 \frac{1}{2} \mathrm{lb}$. in weight in two months. The child sometimes seemed rather pale and weak. She was ordered to take only one tablet daily. On the 21st the patient seemed better and was ordered to resume taking one and a half tablets daily. On April 20th her height was $3 \mathrm{ft} .6$ in.

1 We regret that the photographs sent by Surgeon-Captain DrakeBrockman to illustrate the good progress of this case were not suitable for reproduction, but the notes tell the story perfectly clearly without them.-ED. L. 